\title{
The Schistosoma mansoni Hepatic Egg Granuloma Provides a Favorable Microenvironment for Sustained Growth of Leishmania donovani
}

\author{
Mohammed F. Hassan, Yaobi Zhang, \\ Christian R. Engwerda, Paul M. Kaye, \\ Hannah Sharp, and Quentin D. Bickle \\ From the Department of Infectious and Tropical Diseases, \\ Immunology Unit, London School of Hygiene and Tropical \\ Medicine, London, United Kingdom
}

Parasitic co-infections are prevalent in many parts of the world. However, relatively little is known about how an underlying infection may impact on the host's ability to control a newly acquired parasite, especially if both infect the same organ. We have studied this using an experimental co-infection model in C57BL/6 mice involving Schistosoma mansoni and Leishmania donovani, two important human pathogens affecting the liver. We show that mice with established $S$. mansoni infections fail to control L. donovani growth in the liver and spleen. The failure occurs despite the development of a functional anti- $L$. donovani Th1 response that can mediate granuloma formation and effective clearance of amastigotes from foci of infection in the hepatic parenchyma. Instead, anti-leishmanial immunity fails within the $S$. mansoni egg granuloma, consistent with a lack of L. donovani granuloma assembly in this tissue microenvironment and consequent lack of NO production. Persisting amastigote replication in the $S$. mansoni egg granulomas may thus explain the increased $L$. donovani burden in the liver and spleen. These results may have implications for human $S$. mansoni and L. donovani co-infections and also demonstrate that granulomatous tissue responses to helminth organisms can form a discrete niche facilitating survival of intracellular pathogens. (Am J Pathol 2006, 169:943-953; DOI: 10.2353/ajpath.2006.051319)

There are potentially overlapping distributions of the protozoan parasite Leishmania donovani and the helminths Schistosoma mansoni and Schistosoma hematobium in several countries, most notably in parts of Africa such as the Sudan. ${ }^{1,2}$ The likelihood of human schistosome/
L. donovani co-infections occurring is increased by their chronicity, the spread of schistosomiasis through irrigation, and the displacement of people between endemic areas. $^{3}$ L. donovani and S. mansoni both induce hostprotective granulomas in the liver but these contrast in being mediated by Th1 or Th2 responses, respectively, ${ }^{4,5}$ giving the potential for immunomodulation, failure of control, and enhanced pathology. Latent L. donovani infection can give rise to severe reactivation disease after human immunodeficiency virus co-infection, ${ }^{6}$ but nothing has been reported on the effects of worm infections in general, and schistosomiasis in particular, on progression of $L$. donovani co-infection or vice versa.

Members of the Leishmania donovani complex ( $L$. donovani, L. infantum, L. chagasi) infect macrophages of the liver, spleen, and bone marrow, and in experimental mouse models the infection is controlled in the liver by the formation of Th1-dependent granulomas around amastigote-infected macrophages. ${ }^{5,7}$ Severity of the infection in humans is influenced by the balance of Th1 (interferon- $\gamma$; IFN- $\gamma$ ), Th2 (interleukin-4; IL-4), and regulatory (IL-10) cytokines, resistance being associated with IFN- $\gamma$ production, ${ }^{8-12}$ and susceptibility with deficient production of IFN- $\gamma, \mathrm{IL}-2$, and IL-12 but increased production of IL-4 and IL-10. ${ }^{11-14}$ Prior induction of a Th2-biased anti-leishmanial response in mice promotes enhanced $L$. donovani proliferation $^{15}$ and experiments with $\mathrm{LL}-10$-deficient mice ${ }^{16} \mathrm{IL}-10$ blockade and $\mathrm{IL}-10$ transgenic mice ${ }^{17}$ have specifically implicated IL-10 as inhibiting immunity.

Schistosome infections are associated with a strong Th2 biased cytokine response in both mice ${ }^{18-20}$ and chronically infected humans. ${ }^{21,22}$ Induction of the Th2 response is caused by the schistosome eggs ${ }^{18,23,24}$ and, in the case of S. mansoni, results in the formation of circum-oval granulomas in the liver. Th2 cytokines control immunopathology,

Supported in part by the Wellcome Trust (grant GR058931MA) and the Embassy of the Arab Republic, Egypt (to M.F.H.).

Accepted for publication May 16, 2006.

Address reprint requests to Dr. Quentin Bickle, Department of Infectious and Tropical Diseases, London School of Hygiene and Tropica Medicine, Keppel St., London, WC1E 7HT, UK. E-mail: quentin. bickle@lshtm.ac.uk. 
with IL-4 driving the Th2 response ${ }^{20}$ and IL-13 inducing the fibrosis that underlies schistosome pathology. ${ }^{25}$ Th1 cytokines (IFN- $\gamma$ and IL-12) play a modulatory role ${ }^{26-28}$ but must themselves be regulated to prevent proinflammatory disease. ${ }^{29-31}$ The regulatory cytokine $\mathrm{IL}-10$ is prominent in schistosome infections, ${ }^{32,33}$ being able to down-regulate both Th1 ${ }^{32,34}$ and Th2 $2^{35}$ cytokine production and limit hepatic granuloma size..$^{34-36}$

The biased Th2 response and the induction of IL-10 in schistosomiasis has been implicated in the down-modulation of bystander Th1 responses to vaccine and autoantigens ${ }^{37-39}$ and to a variety of co-infections, ${ }^{40}$ including Leishmania major. ${ }^{41}$ There is particular interest in concurrent hepatic infection. For example, humans infected with hepatitis B and C (HBV and HCV) show increased incidence of hepatitis, more rapid progression to liver disease, and/or increased mortality, if co-infected with $S$. mansoni. ${ }^{42-44}$ For $\mathrm{HCV}$, this is associated with reduced antigen-specific $\mathrm{CD}^{+}{ }^{+} \mathrm{T}$-cell responses including IFN- $\gamma$ production. ${ }^{45}$ Experimentally, both vaccinia virus ${ }^{46}$ and lymphocytic choriomeningitis virus (LCMV) ${ }^{47}$ infections of S. mansoni-infected mice are characterized by enhanced viral replication in the liver, and notably in the region of the schistosome egg granulomas. ${ }^{47,48}$ In the case of vaccinia virus, this is associated with a switch from a Th1 to a Th2 cytokine response to viral antigens. ${ }^{46,47}$

The present study was designed to determine the reciprocal effects of an established S. mansoni infection and a superimposed $L$. donovani infection. The results show that co-infected mice failed to control $L$. donovani infection, but although there was a delay in the development of a leishmanial-specific Th1 response, this did not affect the formation of granulomas or expression of leishmanicidal activity targeted at $L$. donovani amastigotes found within the liver parenchyma. In contrast, granulomas failed to form around amastigotes found within the hepatic egg granulomas and effective microbicidal responses were lacking. Thus, the hepatic egg granuloma provides a unique niche for persistent $L$. donovani infection.

\section{Materials and Methods}

\section{Mice and Parasites}

Female C57BL/6 mice were purchased from Charles River UK (Margate, Kent, UK) and housed under conventional conditions. S. mansoni of the Puerto Rican strain was maintained in mice and Biomphalaria glabrata snails. For mouse infections, cercariae were obtained from infected snails, counted, and applied percutaneously by the ring method ${ }^{49}$ to mice anesthetized with $110 \mathrm{mg} / \mathrm{kg}$ ketamine hydrochloride (Ketaset; Fort Dodge Animal Health Ltd., Southampton, UK) plus 14 mg/kg xylazine (Rompun; Bayer Plc., Newbury, UK). L. donovani (MHOM/ET/67/HU3) was maintained by passage in Syrian hamsters, and amastigotes were isolated from infected spleens as described previously. ${ }^{50}$ Mice were infected with $L$. donovani by injection of $2 \times 10^{7}$ amastigotes via the lateral tail vein. Mice infected with S. mansoni alone, $L$. donovani alone, or with both infections were referred to as $\mathrm{S}, \mathrm{L}$, and $\mathrm{S} / \mathrm{L}$, respectively.

\section{Determination of Parasite Burden}

S. mansoni worms were recovered by portal perfusion ${ }^{51}$ with perfusion buffer [phosphate buffered saline, 0.02 $\mathrm{U} / \mathrm{ml}$ heparin (monoparin; CP Pharmaceuticals Ltd., Wrexham, UK)]. The worms were washed free of erythrocytes and counted using a dissecting microscope. For estimation of the liver egg burden, livers were removed and weighed and a piece of known weight frozen at $-20^{\circ} \mathrm{C}$ until needed. Eggs were recovered by incubation of the tissue in $5 \% \mathrm{KOH}$ overnight at $37^{\circ} \mathrm{C}$, and the eggs in $50 \mu \mathrm{l}$ aliquots were counted in triplicate. Hepatic and splenic $L$. donovani burdens were determined from Giemsa-stained impression smears ${ }^{52}$ and expressed as Leishman-Donovan units (the number of amastigotes per 1000 host nuclei, multiplied by the weight of the organ). ${ }^{53}$

\section{In Vitro Restimulation Assay to Determine Cytokine Production}

Spleen cell suspensions were prepared in complete culture medium [RPMI 1640 supplemented with 5\% (v/v) fetal calf serum, $1 \mathrm{mmol} / \mathrm{L}$ L-glutamine, $5 \times 10^{-5} \mathrm{~mol} / \mathrm{L}$ 2-mercaptoethanol, $100 \mathrm{U} / \mathrm{ml}$ penicillin, and $100 \mu \mathrm{g} / \mathrm{ml}$ streptomycin (cRPMI)] by passage through a 70- $\mu \mathrm{m}$ sieve. Red blood cells were lysed in Gey's solution [130 mmol/L $\mathrm{NH}_{4} \mathrm{Cl}, 5$ $\mathrm{mmol} / \mathrm{L} \mathrm{KCl}, 8.4 \mathrm{mmol} / \mathrm{L} \mathrm{Na} \mathrm{HPO}_{4}, 180 \mathrm{mmol} / \mathrm{L} \mathrm{KH}_{2} \mathrm{PO}_{4}$, $5.6 \mathrm{mmol} / \mathrm{L}$ D-glucose, $0.001 \%(\mathrm{w} / \mathrm{v})$ phenol red, $1 \mathrm{mmol} / \mathrm{L}$ $\mathrm{MgCl} .6 \mathrm{H}_{2} \mathrm{O}, 280 \mathrm{mmol} / \mathrm{L} \mathrm{MgSO}{ }_{4} \cdot 7 \mathrm{H}_{2} \mathrm{O}, 1.5 \mathrm{mmol} / \mathrm{L} \mathrm{CaCl}_{2}$, $13 \mathrm{mmol} / \mathrm{L} \mathrm{NaHCO}_{3}$ ] for 8 minutes at room temperature and washed twice in cRPMI. Cells were cultured in flat-bottomed 96-well microtiter plates (Nunc, Roskilde, Denmark) at $5 \times$ $10^{5}$ cells in a final volume of $200 \mu \mathrm{l}$ per well, in the presence of medium alone, $5 \mu \mathrm{g} / \mathrm{ml}$ Con A (Sigma, Poole, UK), 20 $\mu \mathrm{g} / \mathrm{ml}$ soluble $S$. mansoni egg antigen (SEA) kindly supplied by Prof. M. Doenhoff (University of Wales, Bangor, UK) or $10^{7} / \mathrm{ml}$ formalin-fixed L. donovani amastigotes (FLAA) prepared from infected Syrian hamster spleen. All cultures were performed in triplicate and cell culture supernatants harvested at 24 hours for IL-4 and 72 hours for IFN- $\gamma$ and IL-10. Cytokine levels in supernatants were determined by enzyme-linked immunosorbent assay using OptEIA cytokine detection kits (PharMingen, San Diego, CA). Serum cytokine levels were measured using the same reagents.

\section{Histology and Immunohistology}

Paraffin-embedded, formalin-fixed liver tissue was sectioned at 5- $\mu \mathrm{m}$ and stained with hematoxylin and eosin (H\&E). Maturation of $L$. donovani granulomas around amastigote-containing Küpffer cells was defined as previously described. ${ }^{54,55}$ Immunostaining was performed on 6- $\mu \mathrm{m}$ cryosectioned liver tissue. For immunolocalization of mannose receptor expression and $L$. donovani amastigotes, sections were fixed with acetone and stained using $4 \mu \mathrm{g} / \mathrm{ml}$ rat anti-mouse CD206 (Serotec, Kidlington, UK) and/or 1:100 (v/v) immune hamster anti-L. donovani serum followed by $4 \mu \mathrm{g} / \mathrm{ml}$ Alexa Fluor 488 goat anti-rat IgG and/or Alexa Fluor 546 goat anti-hamster IgG, respectively (Molecular Probes Inc., Eugene, OR). Host 
cell nuclei were visualized by incorporation of $100 \mu \mathrm{g} / \mathrm{ml}$ DAPI (4',6-diamino-2-phenylindole; Sigma, Poole, UK). Immunostaining was performed in phosphate-buffered saline containing 1.5\% normal goat serum (Sigma). Controls for the primary antibodies were a matching isotype, IgG2a, monoclonal antibody (Serotec) and normal hamster serum. After staining, the sections were mounted in Prolong Antifade (Molecular Probes).

Sections for staining for mouse inducible nitric-oxide synthase (NOS-2) were fixed using ice-cold $4 \%(\mathrm{w} / \mathrm{v})$ paraformaldehyde and stained using rabbit anti-NOS-2 (Calbiochem, La Jolla, CA) followed by a horseradish peroxidase-conjugated goat anti-rabbit antibody (Sigma). Horseradish peroxidase was visualized using appropriate detection reagents according to the manufacturer's instructions (Vector Laboratories, Peterborough, UK). Sections were counterstained with hematoxylin (Sigma), dehydrated, and mounted for examination.

The density of foci of $L$. donovani infection and amastigote numbers per focus were determined in both H\&Eand anti-L. donovani immunofluorescence-stained sections by examination of 50 adjacent fields (at $\times 400$ or $\times 1000$ magnification). The maturation status of the $L$. donovani granulomas was assessed at $\times 400$ magnification. Essentially similar data were obtained by both H\&E and anti-L. donovani immunostaining, but the data shown here for the density and maturation status of granulomas were from the H\&E analysis, and those for the amastigote counts were from the immunostaining, which allowed more accurate counts when there was heavy schistosome-derived hematin pigment accumulation inside L. donovani-infected macrophages.

\section{Statistics}

The statistical differences between groups were tested using the unpaired Student's t-test with GraphPad Prism 4 software. All data are presented as the mean values \pm SEs.

\section{Results}

A Superimposed L. donovani Infection Has No Effect on the Parasite Burden or Egg-Induced Granuloma Formation of a Pre-Existing

\section{S. mansoni Infection}

To determine the effect of a pre-existing $S$. mansoni infection on a superimposed $L$. donovani infection, mice were infected with 25 S. mansoni cercariae via the percutaneous route. This relatively low dose of cercariae was chosen to produce an infection that was not lethal during the acute phase, but which resulted in sufficient mice having a bisexual, egg-producing infection. Mice were co-infected with $L$. donovani 8 weeks after the schistosome infection, by which time the egg-induced Th2 response is firmly established. ${ }^{19}$ Groups of mice were sacrificed at three time points: 10, 12, and 16 weeks after $S$. mansoni infection $(+2,+4$, and +8 weeks after infection with $L$. donovani). There were no significant differences at any of these time points between the
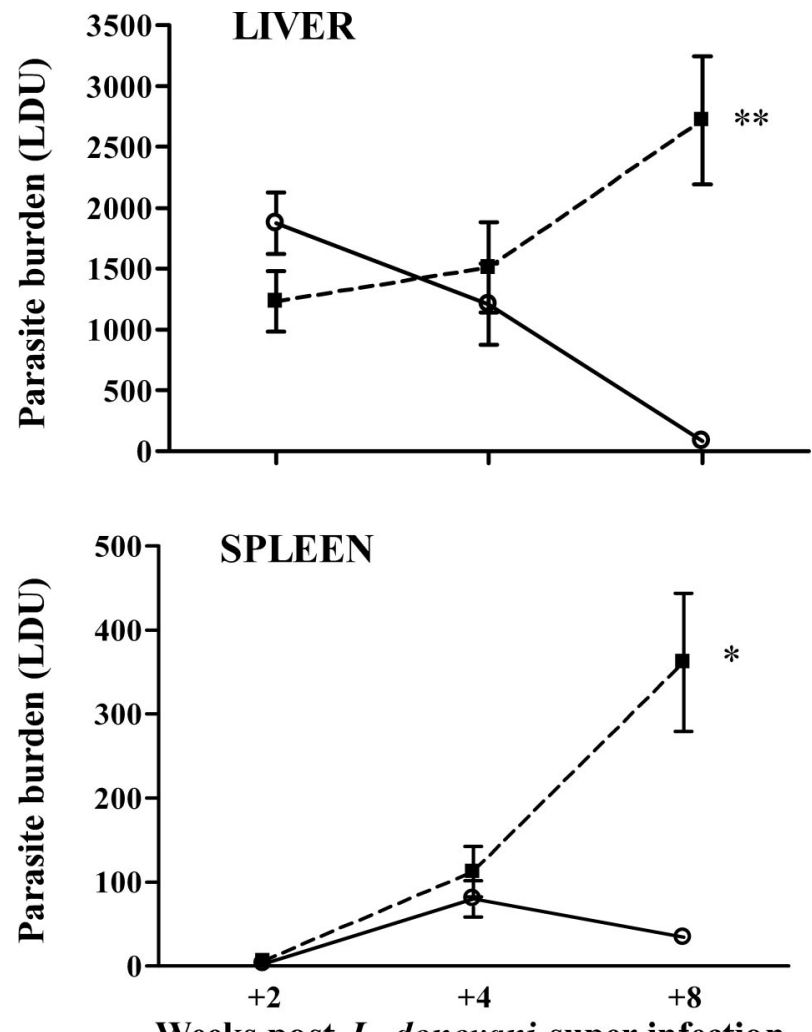

Figure 1. Mice infected with $S$. mansoni fail to control a superimposed $L$. donovani infection in both the liver and the spleen. The figure shows the course of $L$. donovani infection in the livers and spleens of $\mathrm{C} 57 \mathrm{BL} / 6$ mice infected with $L$. donovani alone (L, open circle) or infected with L. donovani at 8 weeks after infection with $25 \mathrm{~S}$. mansoni cercariae (S/L, filled square) Data represent the mean \pm SE Leishman-Donovan unit (LDU) values from five to six mice per group at each time point and are representative of four separate experiments. ${ }^{* *} P<0.001,{ }^{*} P<0.005$.

S. mansoni-infected (S) and the co-infected (S/L) mice in the S. mansoni worm recoveries $(7.5 \pm 2.0,7.5 \pm 4.0,6.4 \pm 3.9$ for the $S$ group and $11.3 \pm 1.7,5.4 \pm 2.9,6.7 \pm 1.8$ for the $\mathrm{S} / \mathrm{L}$ group at $+2,+4$, and +8 weeks, respectively; $n=5$ mice per group) or the liver egg burdens $(20,706 \pm 10,679$, $12,946 \pm 4470,12,102 \pm 5603$ for the $S$ group and $13,323 \pm 4811,10,231 \pm 5828,12,815 \pm 2329$ for the $S / L$ group at $+2,+4$, and +8 weeks, respectively). There was also no significant effect of the $L$. donovani infection on the S. mansoni egg granulomatous response as assessed by the mean granuloma diameters or their cellular composition in $S$ and $S / L$ mice at any time point (data not shown).

\section{The Pre-Existing S. mansoni Infection Results in a Failure to Control the Superimposed \\ L. donovani Infection}

At +2 weeks after $L$. donovani infection, both the $L$ and $S / L$ groups showed similar $L$. donovani parasite burdens (mean LDUs) in the liver (Figure 1). Subsequently, the parasite burden declined progressively in the $L$ mice at +4 and +8 weeks but increased in the $S / L$ mice such that at +8 weeks there was a 33 -fold difference compared with the L mice (2720 $\pm 528 \mathrm{LDU}$ versus $82 \pm 30 \mathrm{LDU}$ for 

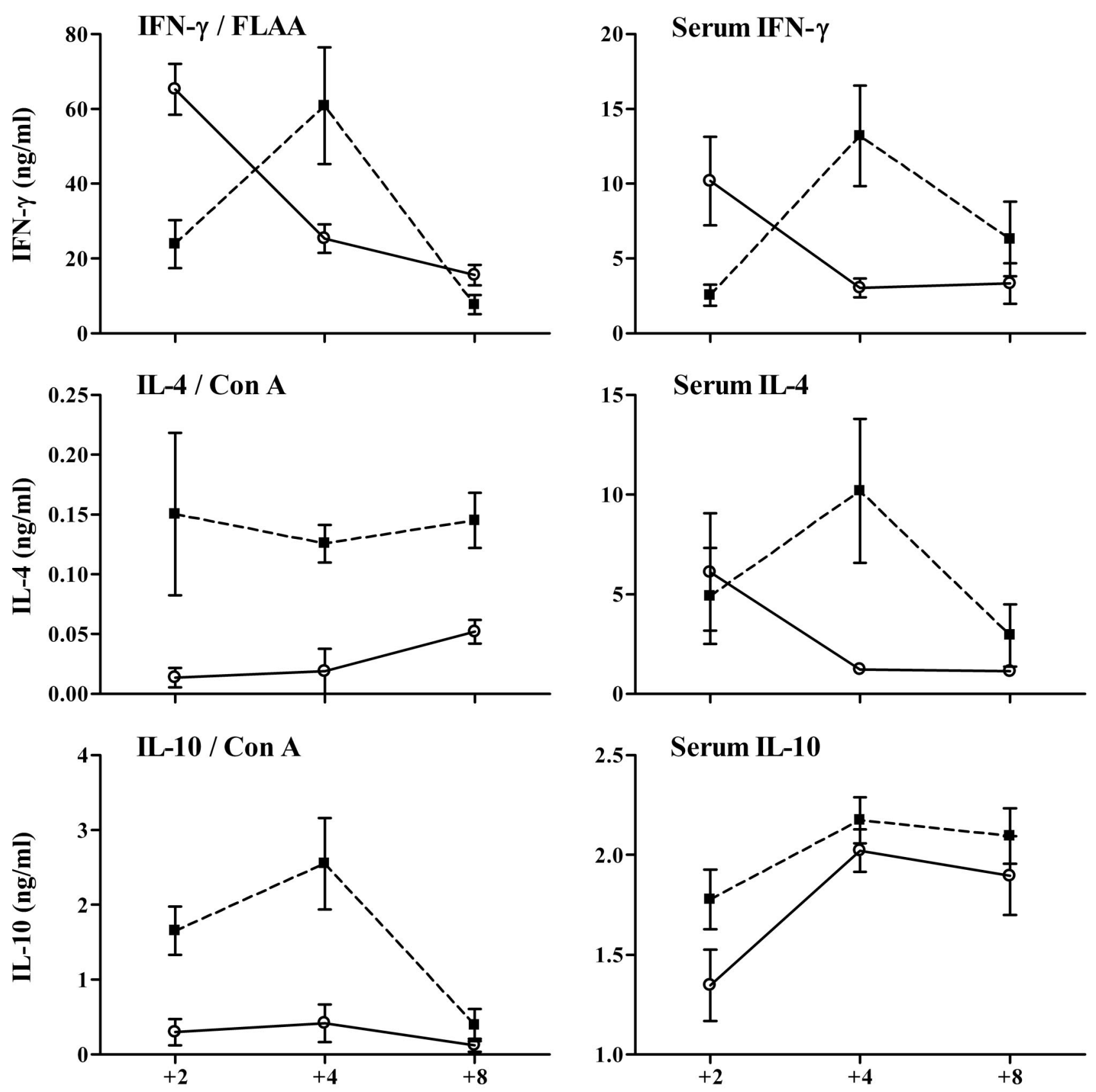

Weeks post $L$. donovani super-infection

Weeks post $L$. donovani super-infection

Figure 2. S/L mice show elevated IL- 4 and IL-10 responses and delayed development of $L$. donovani-specific IFN- $\gamma$ responses compared to L mice. The left graphs show cytokine levels in supernatants of spleen cell cultures stimulated with ConA or formalin-fixed $L$. donovani amastigote antigen (FLAA). The right graphs show serum cytokine levels (mean levels in naïve mouse sera: IFN- $\gamma, 0.393 \pm 0.089$; IL- $4,0.882 \pm 0.017 ; \mathrm{IL}-10,1.450 \pm 0.066 \mathrm{ng} / \mathrm{ml}$ ). Data represent the mean $\pm \mathrm{SE}$ cytokine levels from three mice per group for the splenocyte responses and five mice per group for the serum cytokines at each time point. FLAA-specific and serum IFN- $\gamma$ levels were significantly higher in L mice (open circle) than in S/L mice (filled square) at +2 weeks $(P<0.02)$. Serum IFN- $\gamma$ levels were significantly higher in S/L mice than in L mice at +4 weeks $(P<0.02)$. IL- 4 and IL-10 splenocyte responses were significantly higher in S/L than in L mice (IL- $4: P<0.02$ and $<$ 0.05 at +4 and +8 weeks, respectively; IL-10: $P=0.02$ and $<0.05$ at +2 and +4 weeks, respectively). Serum IL- 4 levels were significantly higher in SL than in $\mathrm{L}$ mice at +4 weeks $(P<0.05)$.

$S / L$ and $L$ groups, respectively). In the spleen, LDUs in both $S / L$ and $L$ mice were low at +2 weeks and increased comparably up to +4 weeks (Figure 1 ). By +8 weeks the level was maintained in the $L$ mice, but in the $S / L$ mice there was a marked increase such that the mean LDU values were 11 -fold higher than in the $L$ mice $(362 \pm 82$ versus $34 \pm 7 \mathrm{LDU}$ for $\mathrm{S} / \mathrm{L}$ and $\mathrm{L}$ groups, respectively).
Comparable and significant disparity between $L$ and $S / L$ LDU values at +8 weeks after superinfection was seen in four separate experiments. S/L mice lost condition beyond +4 weeks after superinfection and 10 to $20 \%$ died or had to be euthanized before the +8 week time point. So it was not possible to extend the study significantly beyond this time. 


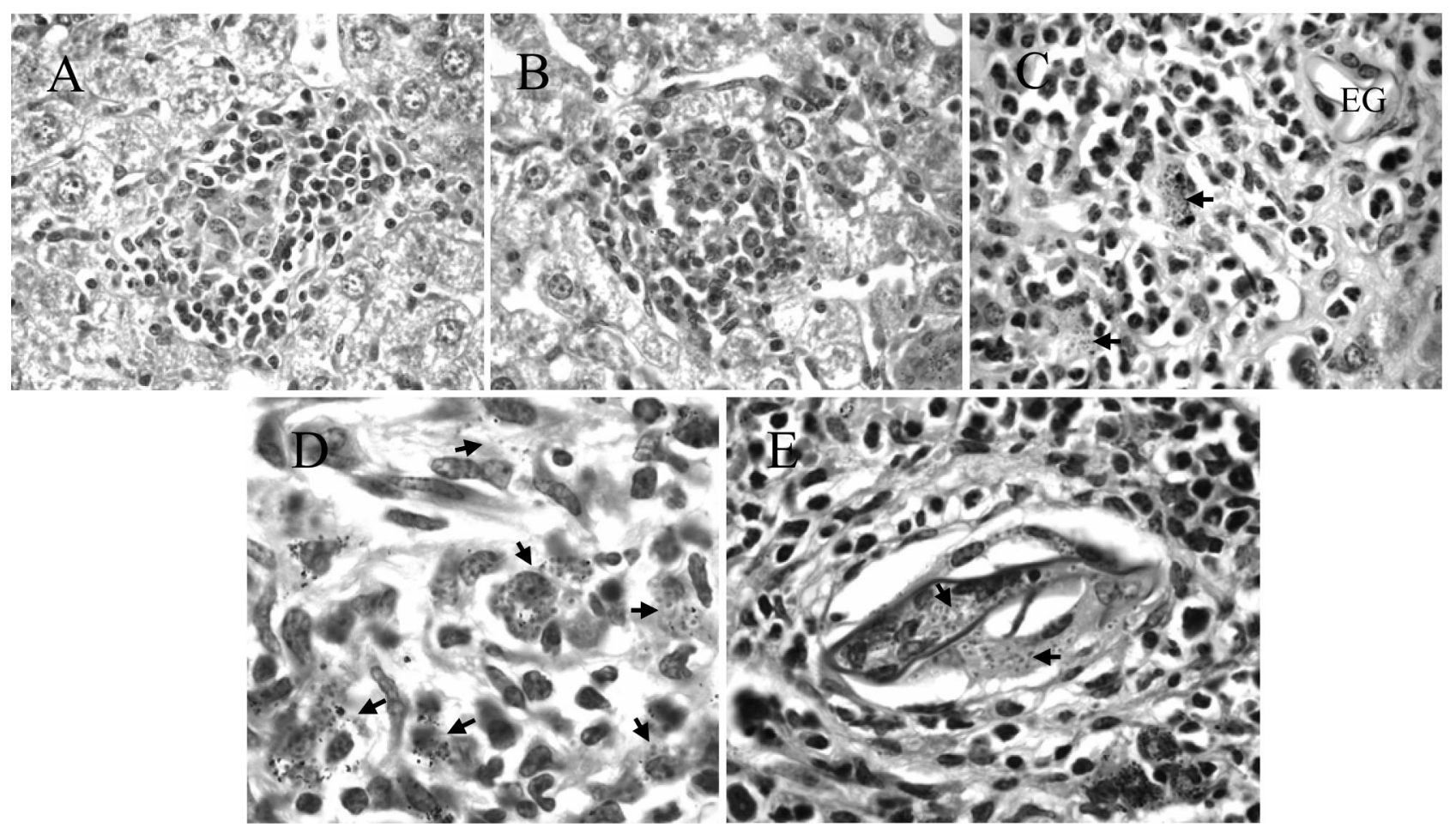

Figure 3. Morphologically normal L. donovani granulomas develop in the liver parenchyma but not in the egg granulomatous areas of S/L mice. H\&E-stained sections of liver show comparable mature L. donovani granulomas in the parenchyma of L (A) and S/L (B) mice. C and D: Dispersed amastigote-laden macrophages (arrows) within the egg granulomas of S/L mice do not elicit discrete cellular foci. EG, S. mansoni egg. E: Heavy accumulation of amastigotes (arrows) within giant cells occupying a schistosome egg shell at the center of an egg granuloma. All sections are from mice at +8 weeks after superinfection. Original magnifications: $\times 400(\mathbf{A}, \mathbf{B}) ; \times 1000(\mathbf{C}, \mathbf{E}) ; \times 1600(\mathbf{D})$.

\section{S/L Mice Show a Delay in Development of L. donovani Antigen-Specific and Serum Levels of IFN- $\gamma$ Associated with Elevated IL-4 and IL-10 Responses}

Cytokine responses were assessed by splenocyte recall responses and serum cytokine levels. Generation of antigen-specific IFN- $\gamma$ is crucial for protection against $L$. donovani $i^{56}$ and so splenocytes from infected mice were restimulated with $L$. donovani antigen (FLAA). L mice produced significantly higher levels of IFN- $\gamma$ compared with the $S / L$ mice at +2 weeks after superinfection (Figure 2). Consistent with earlier reports, ${ }^{16,17}$ the IFN- $\gamma$ response in the $L$ mice dropped progressively between +2 and +8 weeks, but in the S/L mice it increased somewhat between +2 and +4 weeks before falling to a level comparable to that in the $L$ mice at +8 weeks. The $L$. donovanispecific IFN- $\gamma$ levels were not significantly different between $L$ and $S / L$ mice at +4 and +8 weeks. In two other experiments, the FLAA-specific IFN- $\gamma$ production was also significantly higher in $L$ mice than in $S / L$ mice at +2 weeks but not significantly different at either +4 or +8 weeks. Consistent with previous demonstrations that $S$. mansoni infection induces Th2-dominated responses $^{18-20}$ associated with elevated IL-10, ${ }^{32}$ splenocytes from S/L mice showed elevated production of $\mathrm{IL}-4$ and $\mathrm{IL}-10$ in response to ConA compared to $\mathrm{L}$ mice (Figure 2). In contrast, ConA-induced IFN- $\gamma$ levels were not significantly elevated above control levels in any of the infected groups (data not shown). The elevated IL-4 and IL-10 responses in $S / L$ compared with $L$ mice can be related to the schistosome infection, because the $S / L$ mice produced significantly elevated IL-4 and IL-10 in response to the schistosome antigen, SEA (data not shown). This pattern of elevated ConA and schistosome antigen-specific IL-4 and IL-10 production was seen in three separate experiments.

These patterns of recall cytokine responses were consistent with total cytokine levels measured in the serum (Figure 2). Most notably IFN- $\gamma$ levels were again significantly lower in $S / L$ mice compared to $L$ mice at +2 weeks but then rose to significantly higher levels than in $L$ mice at +4 weeks before declining to comparable levels by +8 weeks. As in the splenocyte cultures, serum IL-4 levels were also significantly higher in $S / L$ mice than $L$ mice at +4 weeks. Serum IL-10 levels were elevated in both $S / L$ and $L$ mice, and although IL-10 levels were higher in the $\mathrm{S} / \mathrm{L}$ mice, this was less pronounced than seen by splenocyte recall.

Foci of $\mathrm{L}$. donovani in the Liver of Co-Infected Mice Elicit Morphologically Normal Granulomas in the Parenchyma but Not within the S. mansoni Egg Granulomas

Control of $L$. donovani infection is associated with the formation of granulomas in the liver parenchyma. Foci of infection 
progress from amastigote-infected Küpffer cells to the development of immature and then mature granulomas comprising recruited monocytes, macrophages, neutrophils, and T cells. ${ }^{54,57}$ The production of IFN- $\gamma$ and NO in the mature granulomas is believed to be responsible for killing the amastigotes ${ }^{54}$ resulting in sterile or empty granulomas, each comprising a cellular focus lacking evident amastigotes. Histological analysis of liver sections showed that despite the reduced levels of Leishmania-specific IFN- $\gamma$ in the $\mathrm{S} / \mathrm{L}$ mice at +2 weeks (Figure 2), morphologically normal mature granulomas formed around a proportion of foci of $L$. donovani infection in the liver parenchyma of both $L$ and $S / L$ mice at all time points (Figure 3, A and B). However, unlike the $L$ mice, Küpffer cells laden with schistosome pigment and eosinophils were present in a proportion of the $L$. donovani granulomas in $S / L$ mice. Mice with only S. mansoni infection (S) also showed cellular accumulations in the liver parenchyma associated with Küpffer cells laden with schistosome-derived hematin pigment. Such foci resembled the sterile granulomas in $L$ mice, and so it was not possible to define, or quantitatively compare, sterile granulomas in $\mathrm{S} / \mathrm{L}$ and $\mathrm{L}$ mice.

L. donovani-infected macrophages were also seen within the S. mansoni egg granulomas, but, in contrast to those in the parenchyma, such foci did not elicit defined inflammatory granulomas distinguishable from the pre-existing inflammatory response induced by the eggs (Figure 3C). Rather, they comprised a diffuse collection of amastigoteinfected macrophages (Figure 3D). In S/L mice heavily infected with $L$. donovani, foci of infection extended throughout the egg granulomas including the macrophages or giant cells occupying the empty egg shells at the center of older S. mansoni egg granulomas (Figure 3E).

\section{L. donovani Amastigotes Preferentially Reside within the S. mansoni Egg Granulomas in Co-Infected Animals}

In view of the failure of morphologically normal L. donovani granulomas to form inside the egg granulomas, we were interested to determine whether the increased $L$. donovani amastigote numbers found in the livers of $S / L$ mice were associated with the parenchymal tissue or the schistosome egg granulomas. For this, IFAT staining was performed using anti-L. donovani sera to label the amastigotes, and with antibody to mannose receptor (MR), a marker of alternatively activated macrophages, ${ }^{58}$ which are a feature of the egg granulomas. ${ }^{59}$ As seen in Figure 4A, intense MR staining (green) was restricted to the schistosome egg granulomas, whereas the Küpffer cells throughout the liver stained weakly for MR as previously reported. ${ }^{59}$ Interestingly, none of the cells comprising the $L$. donovani granulomas in the parenchyma of $S / L$ mice showed high expression of mannose receptor, indicating an absence of alternatively activated macrophages either recruited from the schistosome granulomas or activated in situ by Th2 cytokines emanating from the egg granulomas. Notably there was a higher density of amastigotes (red staining) associated with the peripheral regions of the egg granulomas, compared with the foci of infection within the liver
A

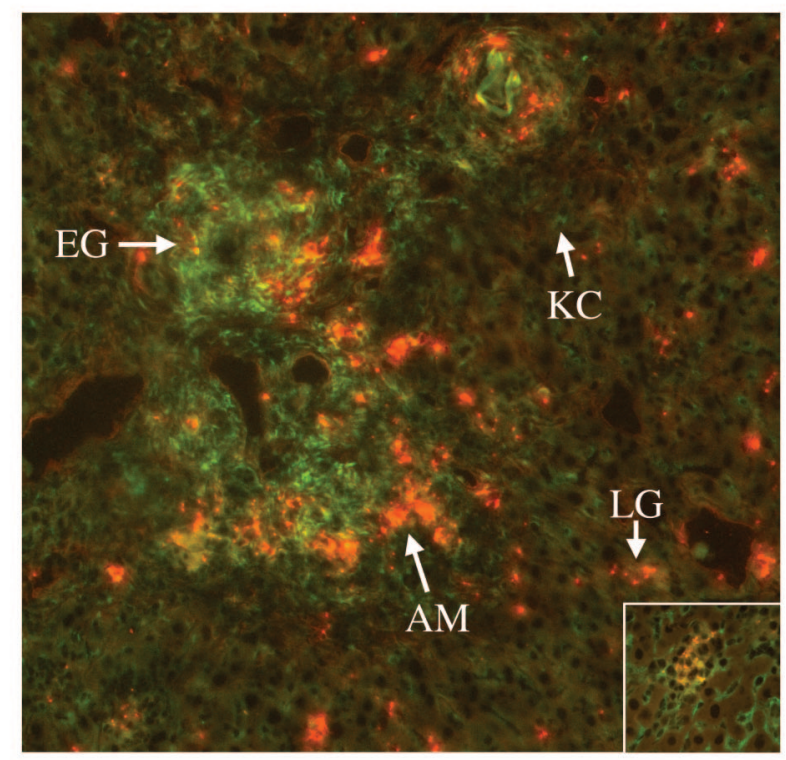

B

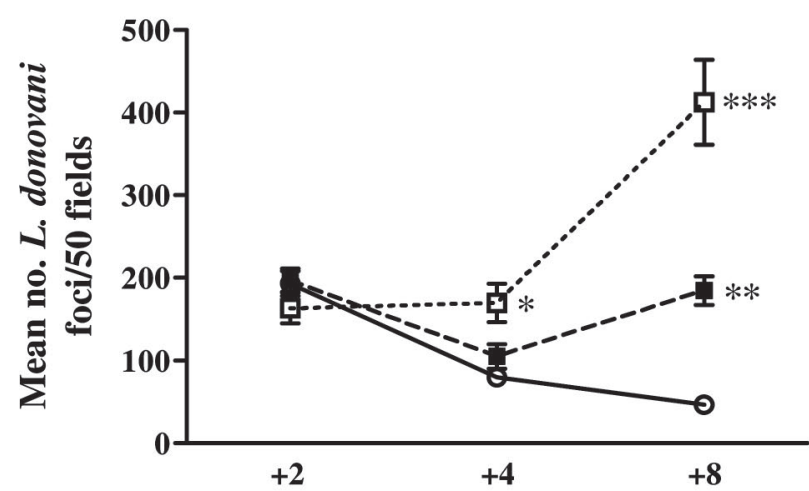

Weeks post $L$. donovani super-infection

Figure 4. Preferential generation of $L$. donovani foci within the schistosome egg granulomatous tissue. A: Liver sections from S/L mice at +8 weeks after co-infection were stained for $L$. donovani amastigotes using immune hamster anti-L. donovani serum and Alexa Fluor 546 goat anti-hamster IgG (red, arrow, AM) and for mannose receptor (MR) with anti-CD 206 and Alexa Fluor 488 goat anti-rat IgG (green). To ensure staining specificity, liver sections from the same S/L mice were stained with isotype control rat IgG2a (control for the MR staining) or normal hamster serum (control for the amastigote staining). No nonspecific staining was seen. Strong specific MR staining can be seen in the granulomatous tissue surrounding the $S$. mansoni eggs (arrow, EG). The parenchymal Küpffer cells stain weakly for MR (arrow, KC), and MR-positive cells are absent from the granulomas surrounding $L$. donovani amastigotes in the parenchyma (inset). A higher density of red-staining $L$. donovani amastigotes can be seen in foci of $L$. donovani infection in the periphery of the $S$. mansoni egg granulomas compared with inside the $L$. donovani granulomas (LG) in the parenchymal tissue. B: This was confirmed quantitatively in H\&E-stained tissue sections by counting the density of $L$. donovani foci in the egg granulomatous tissue of $\mathrm{S} / \mathrm{L}$ mice (S/L G, open square) compared with the surrounding parenchyma (S/L P, filled square) and the parenchyma of $\mathrm{L}$ mice ( $\mathrm{L}$, open circle). For each mouse 50 adjacent fields were counted at $\times 400$ magnification. The data in $\mathbf{B}$ show the mean $\pm \mathrm{SE}$ from five mice per group and is representative of two separate experiments. ${ }^{*} P<0.01$ for $\mathrm{S} / \mathrm{L} \mathrm{G}$ versus $\mathrm{L} ;{ }^{* *} P<0.0001$ for $\mathrm{S} / \mathrm{L} \mathrm{P}$ versus $\mathrm{L} ;{ }^{* * * *} P<0.0001$ for $\mathrm{S} / \mathrm{L} \mathrm{G}$ versus $\mathrm{L}, P<0.005$ for $\mathrm{S} / \mathrm{L} \mathrm{G}$ versus $\mathrm{S} / \mathrm{L} \mathrm{P}$. Original magnifications: $\times 100(\mathbf{A}) ; \times 400(\mathbf{A}$, inset $)$. 
parenchyma, especially at +8 weeks after superinfection (Figure 4A). This observation was supported by quantitative comparison of the densities of foci of infection in either the parenchymal areas or the egg granulomatous areas of the livers of $L$ or $S / L$ mice (Figure $4 B$ ). At just +2 weeks after infection, comparable densities of $L$. donovani foci were found in the parenchyma and in the $S$. mansoni egg granulomatous areas of $L$ and $S / L$ mice. In $L$ mice, the density of foci declined progressively and significantly between +2 , +4 , and +8 weeks $(P<0.001, P<0.05$, respectively) coincident with the decline in parasite burden (Figure 1) and with the development of immunity to $L$. donovani in C57BL/6 mice. ${ }^{54,57}$ In the S/L mice, the density of $L$. donovani foci in the parenchyma initially declined between +2 and +4 weeks but then increased significantly between weeks +4 and $+8(P<0.01)$. The density of $L$. donovani foci within the egg granulomas was comparable at +2 and +4 weeks but showed a marked and significant increase between +4 and +8 weeks $(P<0.005)$. As a consequence, the densities of $L$. donovani foci were significantly higher in both the parenchyma and egg granulomas of the $\mathrm{S} / \mathrm{L}$ mice compared with the $\mathrm{L}$ mice at +8 weeks $(P<$ 0.0001 ) and significantly higher in the granulomatous areas compared with the parenchyma of the $S / L$ mice $(P<0.01)$.

The failure to control $L$. donovani infection within the egg granulomas could result in a persistent source of amastigotes for the continued establishment of new immature foci of infection. Analysis of the ratio of mature reactions relative to immature ones (infected Küpffer cells or immature granulomas) (Figure 5) showed that whereas the proportion of mature granulomas increased progressively in the $L$ mice, associated with the decline in overall parasite numbers, the proportion did not change significantly in the $S / L$ mice throughout time (Figure 5). Although this could be explained by a slower rate of development of mature reactions in $\mathrm{S} / \mathrm{L}$ mice, it seems likely that, in the face of continued parasite replication within the egg granulomas, it simply reflects the continued establishment of new foci of infection. We conclude that the $S$. mansoni egg granuloma is a particularly favorable site for establishment and maintenance of $L$. donovani infection leading to establishment of new foci of infection throughout the liver.

\section{Foci of $\mathrm{L}$. donovani in the Hepatic Parenchyma of Single and of Co-Infected Mice Contain Similar Numbers of Amastigotes}

Like the S/L mice, IL-10 transgenic mice infected with $L$. donovani fail to control the infection. ${ }^{17}$ Infected macrophages in these transgenic mice do not elicit mature granulomas early (+2 weeks) after infection and accumulate large numbers of amastigotes. Even though mature granulomas eventually develop, these also contain heavy amastigote burdens compared with wild-type mice. ${ }^{17}$ Therefore, we investigated if the foci of infection in the parenchyma and egg granulomas of S/L mice were similarly characterized by enhanced amastigote numbers per focus. Because of the large range in amastigote frequencies in any given animal, mean amastigote counts were unhelpful and could hide the presence of a population of heavily infected cells.

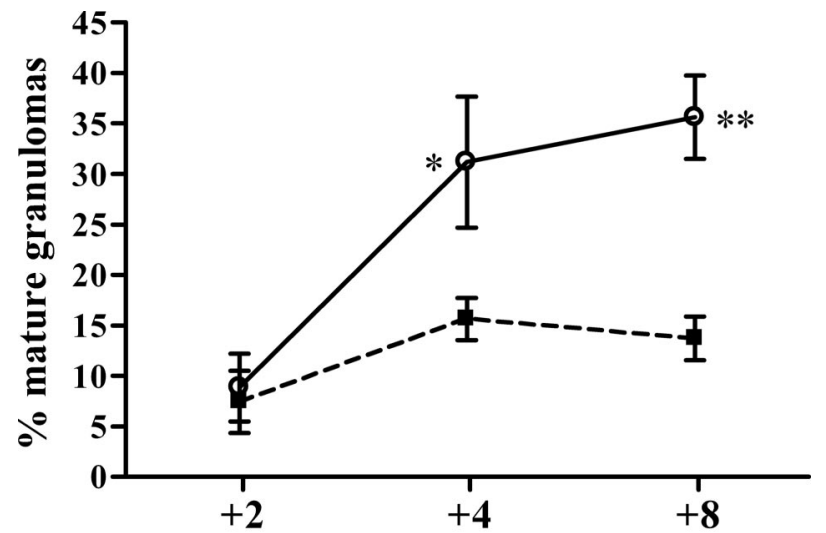

Weeks post $L$. donovani super-infection

Figure 5. The proportion of mature parenchymal L. donovani granulomas in the liver increases progressively in $\mathrm{L}$ mice but not in $\mathrm{S} / \mathrm{L}$ mice. Foci of infection were examined in 50 adjacent fields ( $\times 400$ magnification) of H\&E-stained liver tissue and recorded as L. donovani-infected Küpffer cells, immature or mature granulomas. The data shown are the mean percentages of mature granulomas \pm $\mathrm{SE}$ from the S/L (filled square) and L (open circle) groups and is representative of two separate experiments. Percentages of mature granulomas were significantly higher in $\mathrm{L}$ mice than $\mathrm{S} / \mathrm{L}$ mice at +4 and +8 weeks $(n=5$ mice per group at each time point; ${ }^{*} P<0.05 ;{ }^{* *} P<0.002$ ).

Hence, the data are presented as a frequency distribution (Figure 6). For the small proportion of foci with amastigote counts greater than 50, the amastigote numbers were comparable in foci in the parenchyma and in the S. mansoni granulomas (data not shown). The frequency distribution shows that amastigote burdens within foci of infection in the liver parenchyma of $L$ and $S / L$ mice were comparable at all time points. The parenchymal foci in both the $L$ and $S / L$ mice showed an increasing proportion of low amastigote numbers throughout the time course of the experiment. At +8 weeks there were similar proportions of foci with low numbers of amastigotes (1 to 10) in both $L$ and S/L mice (82 and $72 \%$, respectively). However, in the $L$ mice the majority of such foci were mature (resolving) granulomas (Figure 5), whereas in the $S / L$ mice they comprised newly infected Küpffer cells. Overall there was no evidence of heavy accumulation of amastigotes within the parenchymal foci in the $S / L$ mice indicating that the morphologically normal parenchymal granulomas are able to control infection. The egg granulomas of $S / L$ mice were characterized by persistence of a higher proportion of $L$. donovani foci with moderate numbers of amastigotes (11 to 30 ) compared with the parenchymal foci in $L$ or $S / L$ mice but there was no evidence of accumulation of very heavily parasitized macrophages suggesting that, in the absence of structurally mature $L$. donovani granulomas, the infected macrophages rupture and amastigotes spread.

Foci of L. donovani within the Egg Granulomas of Co-Infected Mice Show Reduced NOS-2 Expression Compared to Foci in the Parenchyma

In susceptible strains, such as the C57BL/6 mice used in these studies, control of $L$. donovani depends on parasite 

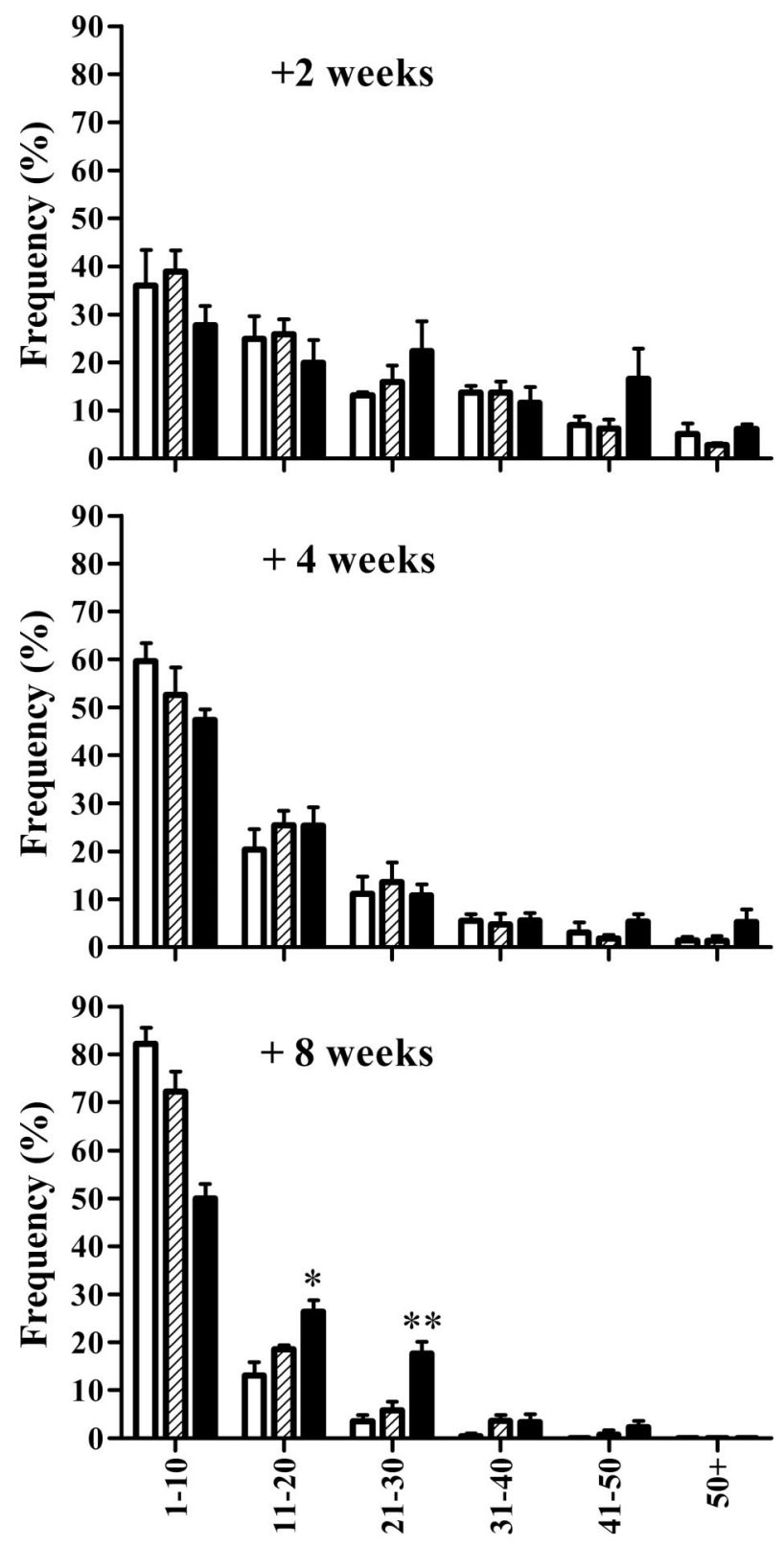

Mean number of amastigotes per focus

Figure 6. The failure of $L$. donovani control in S/L mice is not characterized by heavy accumulation of amastigotes within individual foci. Amastigotes, visualized by staining as described in Figure 4, were counted in individual foci and the frequencies of foci containing differing numbers of amastigotes determined. The data are based on examination of 50 adjacent fields $(\times 1000$ magnification, $n=5$ mice) and is representative of two separate experiments. Data refer to $L$. donovani foci in the parenchyma of $\mathrm{L}$ mice (open bars), the parenchyma of S/L mice (shaded bars), and the egg granulomatous tissue of S/L mice (black bars). "Significantly higher than in the parenchyma of $\mathrm{S} / \mathrm{L}$ mice $(P<0.01)$ and $\mathrm{L}$ mice $(P<0.02)$. ${ }^{* *}$ Significantly higher than in the parenchyma of $\mathrm{S} / \mathrm{L}$ mice $(P<0.01)$ and $\mathrm{L}$ mice $P<0.001)$.

killing by reactive oxygen and nitrogen intermediates. Reactive nitrogen intermediates play the major role ${ }^{60}$ and can be visualized by staining for NOS-2 in hepatic granulomas. ${ }^{57}$ As illustrated in Figure 7B for the +8 -week time point, NOS-2 expression could be demonstrated in $L$. donovani granulomas in the parenchyma of $S / L$ mice and was comparable to that in the $L$ mice (Figure $7 A$ ), sug- gesting that there was no inhibition of leishmanicidal activity in the parenchyma of $S / L$ mice. In contrast, the staining around $L$. donovani foci in the $S$. mansoni egg granulomas was much weaker (Figure 7, B and C). An unexpected finding was the high level of NOS-2 expression surrounding the $S$. mansoni eggs in both $S / L$ and $S$ mice. This very focal staining was typical, and although such expression of NOS-2 within the egg granuloma has been described for $S$. japonicum granulomas in mice, ${ }^{61}$ such staining has only been described around S. mansoni eggs in mice lacking alternatively activated macrophages. ${ }^{30}$ Overall, the intensity of NOS-2 staining associated with the schistosome eggs in S/L mice was greater than that associated with the L. donovani granulomas in a given area of tissue, precluding quantitative comparisons of the NOS-2 expression specifically associated with the L. donovani granulomas. Similar relative intensities of NOS-2 staining in $L$ and $S / L$ mice were also seen at +2 and +4 weeks (data not shown).

\section{Discussion}

These studies showed that S. mansoni-infected mice fail to control a superimposed $L$. donovani infection and suggest that this is not attributable to a generalized failure in the development of effective anti-L. donovani immunity but rather occurs because the $S$. mansoni egg granuloma provides a microenvironment unfavorable for the expression of anti-leishmanial immunity, thus creating a niche for persistent amastigote survival.

Several previous studies have shown suppression of Th1 responses to unrelated antigens/pathogens in the context of Th2 cytokine responses stimulated by schistosome eggs. ${ }^{36,40,45}$ This has been attributed to the anti-inflammatory effects of IL-4 and IL-10, ${ }^{62}$ and can lead to reduced control of concurrent infections. ${ }^{40,45} \mathrm{IL}-4$ and IL-10 can inhibit protective Th1 responses to $L$. donovani ${ }^{15,62,63}$ and, furthermore, induction of a Th2 response by injection of heat-killed L. major promastigotes (HKLM) resulted in failure to control L. donovani, which was dependent on IL-4 and $\mathrm{IL}-10$ and inhibition of IFN- $\gamma{ }^{15} \mathrm{~S} / \mathrm{L}$ mice showed elevated levels of IL-4 and IL-10 compared with $L$ mice, but IFN- $\gamma$ levels were only significantly lower than in $L$ mice at +2 weeks after superinfection. By +4 and +8 weeks IFN- $\gamma$ levels were higher or comparable to those in $L$ mice. We consistently observed highly elevated LDUs in S/L compared with $L$ mice at +8 weeks after superinfection, but no coincident significant differences in IFN- $\gamma$ responses.

IFN- $\gamma$ induces development of mature granulomas around $L$. donovani-infected Küpffer cells ${ }^{64,65}$ and these mediate amastigote killing. ${ }^{5,56}$ In Th2-skewed mice, mature granulomas formed but at a reduced frequency that was attributed to a failure of granuloma assembly in the Th2 environment. ${ }^{15}$ Morphologically mature granulomas also formed in the hepatic parenchyma of S/L mice (Figure 3), but at a lower frequency than in $L$ mice at +4 and +8 weeks (Figure 5). However, we interpret this lower frequency as being attributable to the increased frequency of immature granulomas (Figure 4B) arising from 

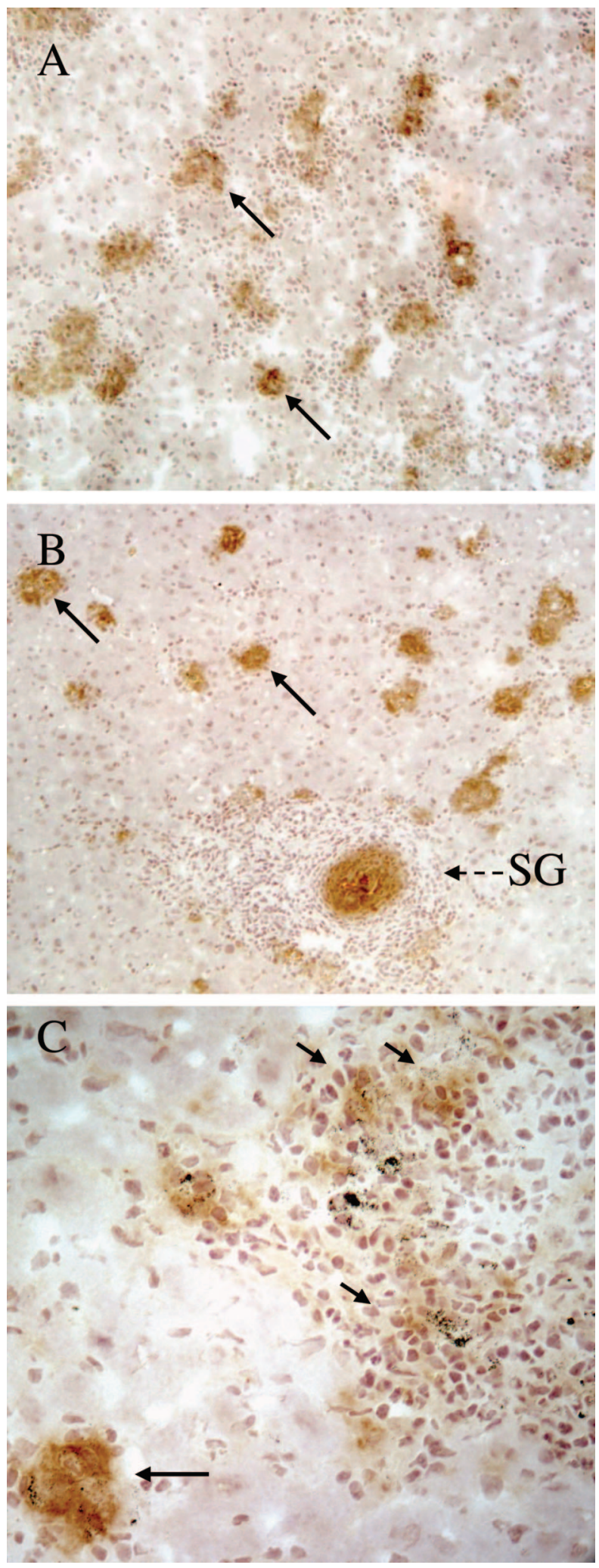

Figure 7. NOS-2 expression around foci of L. donovani replication is comparable in the liver parenchyma of $\mathrm{L}$ and $\mathrm{S} / \mathrm{L}$ mice but inhibited within the $S$ mansoni egg granulomas. NOS-2-stained liver sections from L mice (A), S/L mice (B and $\mathbf{C}$ ) 8 weeks after $L$. donovani infection. Long arrows: granulomas in parenchyma showing strong NOS-2 staining. Short arrows: low intensity NOS-2 staining around $L$. donovani foci associated with the $S$. mansoni egg granulomas. SG, schistosome egg granuloma showing strong NOS-2 staining around the egg. Original magnifications: $\times 100(\mathbf{A}, \mathbf{B}) ; \times 400$ (C). the uncontrolled parasite replication in $S / L$ mice, rather than impaired granuloma maturation.

Ultimately, killing of $L$. donovani amastigotes within the mature granulomas requires activation of granuloma macrophages by TNF- $\alpha$ and IFN- $\gamma^{56,66}$ leading to NOS-2 expression and generation of high and persistent levels of NO. ${ }^{60,67} \mathrm{IL}-10$ serves to inhibit NOS-2 expression and promotes $L$. donovani infection. ${ }^{16,17}$ Thus, hepatic granulomas in IL-10 transgenic mice showed severely inhibited NOS-2 expression and contained very high amastigote numbers indicating suppressed leishmanicidal activity. ${ }^{17}$ In contrast, S/L mice did not show inhibited NOS-2 expression within mature granulomas in the liver parenchyma (Figure 7) nor uncontrolled amastigote replication within individual foci (Figure 6), suggesting that the elevated IL-10 was insufficient to inhibit leishmanicidal activity in the parenchyma.

The abundant schistosome egg granuloma macrophages ${ }^{68}$ provide a potential niche for $L$. donovani infection in the liver of $S / L$ mice, and early during infection we found comparable levels of $L$. donovani infection in the parenchyma and egg granulomas. Subsequently, and coincident with the manifestation of anti-L. donovani immunity in the $L$ mice, ${ }^{54}$ the density of foci in the egg granulomas increased relative to the parenchyma in the $S / L$ mice (Figure 4 ). Notably, such foci failed to elicit histologically discrete granulomas and showed low levels of NOS-2 expression, compared to foci in the parenchyma of $S / L$ and $L$ mice.

There are various ways in which development of the Th1-mediated anti-L. donovani immunity could be inhibited within the egg granulomas, which are themselves highly regulated, to limit excessive Th1- or Th2-mediated pathology. ${ }^{31}$ High levels of IL-4 endogenously produced by the egg granuloma cells ${ }^{69}$ could inhibit proliferation of Th1 cells. High levels of IL-10 produced by regulatory $\mathrm{CD} 4^{+} \mathrm{CD}_{25}{ }^{+}$cells and macrophages in the granulomas can inhibit both Th2 and Th1 responses ${ }^{69-72}$ and the abundant alternatively activated macrophages are crucial in preventing severe Th1-dependent inflammatory disease. ${ }^{30,59,73,74}$ Alternatively activated macrophages may also provide a nutritionally privileged site for Leishmania amastigotes because arginase I appears to promote parasite growth ${ }^{75}$ by generating L-ornithine, the substrate for biosynthesis of polyamines used for parasite growth and differentiation. ${ }^{76,77}$

In conclusion, these results suggest that despite developing a Th2-skewed cytokine response, S/L mice develop a delayed but apparently functional anti- $L$. donovani Th1 response that is able to mediate granuloma formation and effective clearance of amastigotes from foci of infection in the hepatic parenchyma. However, this anti-leishmanial immunity fails in foci of infection within the $S$. mansoni egg granuloma probably owing to the lack of $L$. donovani granuloma assembly and the consequent lack of expression of NO. This persisting source of amastigotes would thus explain the maintenance of $L$. donovani in the liver in $S / L$ mice. The results suggest that control of $L$. donovani infection may be inhibited in S. mansoni co-infected humans, and this warrants further investigation. 


\section{References}

1. Hoogstraal H, Heyneman D: Leishmaniais in the Sudan Republic 30. Final epidemiological report. Am J Trop Med Hyg 1969 , 18:1091-1210

2. el Gaddal AA: The Blue Nile Health Project: a comprehensive approach to the prevention and control of water-associated diseases in irrigated schemes of the Sudan. J Trop Med Hyg 1985 88:47-56

3. Zijlstra EE, Ali MS, el-Hassan AM, el-Toum IA, Satti M, Ghalib HW, Sondorp E, Winkler A: Kala-azar in displaced people from southern Sudan: epidemiological, clinical and therapeutic findings. Trans R Soc Trop Med Hyg 1991, 85:365-369

4. Pearce EJ, C MK, Sun J, Taylor JJ, McKee AS, Cervi L: Th2 response polarization during infection with the helminth parasite Schistosoma mansoni. Immunol Rev 2004, 201:117-126

5. Murray HW: Tissue granuloma structure-function in experimental visceral leishmaniasis. Int J Exp Pathol 2001, 82:249-267

6. Alvar J, Canavate C, Gutierrez-Solar B, Jimenez M, Laguna F, LopezVelez R, Molina R, Moreno J: Leishmania and human immunodeficiency virus coinfection: the first 10 years. Clin Microbiol Rev 1997 10:298-319

7. Kaye PM, Svensson M, Ato M, Maroof A, Polley R, Stager S, Zubairi S, Engwerda CR: The immunopathology of experimental visceral leishmaniasis. Immunol Rev 2004, 201:239-253

8. Bacellar O, Barral-Netto M, Badaro R, Carvalho EM: Gamma interferon production by lymphocytes from children infected with $L$. chagasi. Braz J Med Biol Res 1991, 24:791-795

9. Carvalho EM, Barral A, Pedral-Sampaio D, Barral-Netto M, Badaro R, Rocha H, Johnson Jr WD: Immunologic markers of clinical evolution in children recently infected with Leishmania donovani chagasi. J Infect Dis 1992, 165:535-540

10. Ghalib HW, Piuvezam MR, Skeiky YA, Siddig M, Hashim FA, elHassan AM, Russo DM, Reed SG: Interleukin 10 production correlates with pathology in human Leishmania donovani infections. J Clin Invest 1993, 92:324-329

11. Carvalho EM, Bacellar O, Brownell C, Regis T, Coffman RL, Reed SG Restoration of IFN-gamma production and lymphocyte proliferation in visceral leishmaniasis. J Immunol 1994, 152:5949-5956

12. Bacellar O, Brodskyn C, Guerreiro J, Barral-Netto M, Costa $\mathrm{CH}$, Coffman RL, Johnson WD, Carvalho EM: Interleukin-12 restores interferon-gamma production and cytotoxic responses in visceral leishmaniasis. J Infect Dis 1996, 173:1515-1518

13. Ghalib HW, Whittle JA, Kubin M, Hashim FA, el-Hassan AM, Grabstein KH, Trinchieri G, Reed SG: IL-12 enhances Th1-type responses in human Leishmania donovani infections. J Immunol 1995 154:4623-4629

14. Carvalho EM, Badaro R, Reed SG, Jones TC, Johnson Jr WD: Absence of gamma interferon and interleukin 2 production during active visceral leishmaniasis. J Clin Invest 1985, 76:2066-2069

15. Murray HW, Hariprashad J, Coffman RL: Behavior of visceral Leishmania donovani in an experimentally induced T helper cell 2 (Th2) associated response model. J Exp Med 1997, 185:867-874

16. Murphy ML, Wille U, Villegas EN, Hunter CA, Farrell JP: IL-10 mediates susceptibility to Leishmania donovani infection. Eur J Immunol 2001, 31:2848-2856

17. Murray HW, Lu CM, Mauze S, Freeman S, Moreira AL, Kaplan G, Coffman RL: Interleukin-10 (IL-10) in experimental visceral leishmaniasis and IL-10 receptor blockade as immunotherapy. Infect Immun 2002, 70:6284-6293

18. Pearce EJ, Caspar P, Grzych JM, Lewis FA, Sher A: Downregulation of Th1 cytokine production accompanies induction of Th2 responses by a parasitic helminth, Schistosoma mansoni. J Exp Med 1991 173:159-166

19. Grzych JM, Pearce E, Cheever A, Caulada ZA, Caspar P, Heiny S, Lewis F, Sher A: Egg deposition is the major stimulus for the production of Th2 cytokines in murine schistosomiasis mansoni. J Immunol 1991, 146:1322-1327

20. Wynn TA, Eltoum I, Cheever AW, Lewis FA, Gause WC, Sher A: Analysis of cytokine mRNA expression during primary granuloma formation induced by eggs of Schistosoma mansoni. J Immunol 1993, 151:1430-1440

21. Araujo MI, de Jesus AR, Bacellar O, Sabin E, Pearce E, Carvalho EM:
Evidence of a $\mathrm{T}$ helper type 2 activation in human schistosomiasis. Eur J Immunol 1996, 26:1399-1403

22. de Jesus AR, Magalhaes A, Miranda DG, Miranda RG, Araujo MI, de Jesus AA, Silva A, Santana LB, Pearce E, Carvalho EM: Association of type 2 cytokines with hepatic fibrosis in human Schistosoma mansoni infection. Infect Immun 2004, 72:3391-3397

23. Okano M, Satoskar AR, Nishizaki K, Abe M, Harn Jr DA: Induction of Th2 responses and IgE is largely due to carbohydrates functioning as adjuvants on Schistosoma mansoni egg antigens. J Immunol 1999, 163:6712-6717

24. MacDonald AS, Straw AD, Bauman B, Pearce EJ: CD8-dendritic cell activation status plays an integral role in influencing Th2 response development. J Immunol 2001, 167:1982-1988

25. Chiaramonte MG, Schopf LR, Neben TY, Cheever AW, Donaldson DD, Wynn TA: IL-13 is a key regulatory cytokine for Th2 cell-mediated pulmonary granuloma formation and $\operatorname{lgE}$ responses induced by Schistosoma mansoni eggs. J Immunol 1999, 162:920-930

26. Dessein AJ, Hillaire D, Elwali NE, Marquet S, Mohamed-Ali Q, Mirghani A, Henri S, Abdelhameed AA, Saeed OK, Magzoub MM, Abel $\mathrm{L}$ : Severe hepatic fibrosis in Schistosoma mansoni infection is controlled by a major locus that is closely linked to the interferon-gamma receptor gene. Am J Hum Genet 1999, 65:709-721

27. Wynn TA, Eltoum I, Oswald IP, Cheever AW, Sher A: Endogenous interleukin 12 (IL-12) regulates granuloma formation induced by eggs of Schistosoma mansoni and exogenous IL-12 both inhibits and prophylactically immunizes against egg pathology. J Exp Med 1994, 179:1551-1561

28. Henri S, Chevillard C, Mergani A, Paris P, Gaudart J, Camilla C, Dessein H, Montero F, Elwali NE, Saeed OK, Magzoub M, Dessein $\mathrm{AJ}$ : Cytokine regulation of periportal fibrosis in humans infected with Schistosoma mansoni: IFN-gamma is associated with protection against fibrosis and TNF-alpha with aggravation of disease. J Immunol 2002, 169:929-936

29. Brunet LR, Finkelman FD, Cheever AW, Kopf MA, Pearce EJ: IL-4 protects against TNF-alpha-mediated cachexia and death during acute schistosomiasis. J Immunol 1997, 159:777-785

30. Herbert DR, Holscher C, Mohrs M, Arendse B, Schwegmann A Radwanska M, Leeto M, Kirsch R, Hall P, Mossmann H, Claussen B, Forster I, Brombacher F: Alternative macrophage activation is essential for survival during schistosomiasis and downmodulates Thelper 1 responses and immunopathology. Immunity 2004, 20:623-635

31. Hoffmann KF, Cheever AW, Wynn TA: IL-10 and the dangers of immune polarization: excessive type 1 and type 2 cytokine responses induce distinct forms of lethal immunopathology in murine schistosomiasis. J Immunol 2000, 164:6406-6416

32. Sher A, Fiorentino D, Caspar P, Pearce E, Mosmann T: Production of IL-10 by CD4+ T lymphocytes correlates with down-regulation of Th1 cytokine synthesis in helminth infection. J Immunol 1991, 147:2713-2716

33. King CL, Medhat A, Malhotra I, Nafeh M, Helmy A, Khaudary J, Ibrahim S, El-Sherbiny M, Zaky S, Stupi RJ, Brustoski K, Shehata M, Shata MT: Cytokine control of parasite-specific anergy in human urinary schistosomiasis. IL-10 modulates lymphocyte reactivity. J Immunol 1996, 156:4715-4721

34. Wynn TA, Cheever AW, Williams ME, Hieny S, Caspar P, Kuhn R, Muller W, Sher A: IL-10 regulates liver pathology in acute murine Schistosomiasis mansoni but is not required for immune down-modulation of chronic disease. J Immunol 1998, 160:4473-4480

35. Sadler CH, Rutitzky LI, Stadecker MJ, Wilson RA: IL-10 is crucial for the transition from acute to chronic disease state during infection of mice with Schistosoma mansoni. Eur J Immunol 2003, 33:880-888

36. Flores-Villanueva PO, Zheng XX, Strom TB, Stadecker MJ: Recombinant IL-10 and IL-10/Fc treatment down-regulate egg antigen-specific delayed hypersensitivity reactions and egg granuloma formation in schistosomiasis. J Immunol 1996, 156:3315-3320

37. Sabin EA, Araujo MI, Carvalho EM, Pearce EJ: Impairment of tetanus toxoid-specific Th1-like immune responses in humans infected with Schistosoma mansoni. J Infect Dis 1996, 173:269-272

38. Cooke A, Tonks P, Jones FM, O'Shea H, Hutchings P, Fulford AJ, Dunne DW: Infection with Schistosoma mansoni prevents insulin dependent diabetes mellitus in non-obese diabetic mice. Parasite Immunol 1999, 21:169-176

39. Sewell D, Qing Z, Reinke E, Elliot D, Weinstock J, Sandor M, Fabry Z: 
Immunomodulation of experimental autoimmune encephalomyelitis by helminth ova immunization. Int Immunol 2003, 15:59-69

40. Cox FE: Concomitant infections, parasites and immune responses. Parasitology 2001, 122:S23-S38

41. La Flamme AC, Scott P, Pearce EJ: Schistosomiasis delays lesion resolution during Leishmania major infection by impairing parasite killing by macrophages. Parasite Immunol 2002, 24:339-345

42. Madwar MA, el Tahawy M, Strickland GT: The relationship between uncomplicated schistosomiasis and hepatitis B infection. Trans R Soc Trop Med Hyg 1989, 83:233-236

43. Kamal S, Madwar M, Bianchi L, Tawil AE, Fawzy R, Peters T, Rasenack JW: Clinical, virological and histopathological features: longterm follow-up in patients with chronic hepatitis $\mathrm{C}$ co-infected with $\mathrm{S}$. mansoni. Liver 2000, 20:281-289

44. Kamal SM, Rasenack JW, Bianchi L, Al Tawil A, El Sayed Khalifa K, Peter T, Mansour H, Ezzat W, Koziel M: Acute hepatitis C without and with schistosomiasis: correlation with hepatitis C-specific CD4(+) T-cell and cytokine response. Gastroenterology 2001, 121:646-656

45. Kamal SM, Graham CS, He Q, Bianchi L, Tawil AA, Rasenack JW, Khalifa KA, Massoud MM, Koziel MJ: Kinetics of intrahepatic hepatitis $\mathrm{C}$ virus (HCV)-specific CD4+ T cell responses in HCV and Schistosoma mansoni coinfection: relation to progression of liver fibrosis. $\mathrm{J}$ Infect Dis 2004, 189:1140-1150

46. Actor JK, Shirai M, Kullberg MC, Buller RM, Sher A, Berzofsky JA: Helminth infection results in decreased virus-specific CD8+ cytotoxic T-cell and Th1 cytokine responses as well as delayed virus clearance. Proc Natl Acad Sci USA 1993, 90:948-952

47. Edwards MJ, Buchatska O, Ashton M, Montoya M, Bickle QD, Borrow $P$ : Reciprocal immunomodulation in a schistosome and hepatotropic virus coinfection model. J Immunol 2005, 175:6275-6285

48. Actor JK, Marshall MA, Eltoum IA, Buller RM, Berzofsky JA, Sher A: Increased susceptibility of mice infected with Schistosoma mansoni to recombinant vaccinia virus: association of viral persistence with egg granuloma formation. Eur J Immunol 1994, 24:3050-3056

49. Smithers SR, Terry RJ: The infection of laboratory hosts with cercariae of Schistosoma mansoni and the recovery of the adult worms. Parasitology 1965, 55:695-700

50. Kaye PM, Curry AJ, Blackwell JM: Differential production of Th1- and Th2-derived cytokines does not determine the genetically controlled or vaccine-induced rate of cure in murine visceral leishmaniasis. J Immunol 1991, 146:2763-2770

51. Doenhoff M, Bickle Q, Long E, Bain J, McGregor A: Factors affecting the acquisition of resistance against Schistosoma mansoni in the mouse. I. Demonstration of resistance to reinfection using a model system that involves perfusion of mice within three weeks of challenge. J Helminthol 1978, 52:173-186

52. Engwerda CR, Murphy ML, Cotterell SE, Smelt SC, Kaye PM: Neutralization of IL-12 demonstrates the existence of discrete organspecific phases in the control of Leishmania donovani. Eur $\mathrm{J}$ Immunol 1998, 28:669-680

53. Stauber L: Host resistance to the genus Leishmania. Rice Inst Pamph 1958, 45:80-96

54. McElrath MJ, Murray HW, Cohn ZA: The dynamics of granuloma formation in experimental visceral leishmaniasis. J Exp Med 1988, 167:1927-1937

55. Murphy ML, Cotterell SE, Gorak PM, Engwerda CR, Kaye PM: Blockade of CTLA-4 enhances host resistance to the intracellular pathogen, Leishmania donovani. J Immunol 1998, 161:4153-4160

56. Taylor AP, Murray HW: Intracellular antimicrobial activity in the absence of interferon-gamma: effect of interleukin-12 in experimental visceral leishmaniasis in interferon-gamma gene-disrupted mice. $J$ Exp Med 1997, 185:1231-1239

57. Engwerda CR, Ato M, Stager S, Alexander CE, Stanley AC, Kaye PM: Distinct roles for lymphotoxin-alpha and tumor necrosis factor in the control of Leishmania donovani infection. Am J Pathol 2004, 165:2123-2133

58. Stein M, Keshav S, Harris N, Gordon S: Interleukin 4 potently enhances murine macrophage mannose receptor activity: a marker of alternative immunologic macrophage activation. J Exp Med 1992, 176:287-292

59. Linehan SA, Coulson PS, Wilson RA, Mountford AP, Brombacher F,
Martinez-Pomares L, Gordon S: IL-4 receptor signaling is required for mannose receptor expression by macrophages recruited to granulomata but not resident cells in mice infected with Schistosoma mansoni. Lab Invest 2003, 83:1223-1231

60. Murray HW, Nathan CF: Macrophage microbicidal mechanisms in vivo: reactive nitrogen versus oxygen intermediates in the killing of intracellular visceral Leishmania donovani. J Exp Med 1999, 189:741-746

61. Hirata M, Hirata K, Kage M, Zhang M, Hara T, Fukuma T: Effect of nitric oxide synthase inhibition on Schistosoma japonicum egg-induced granuloma formation in the mouse liver. Parasite Immunol 2001, 23:281-289

62. Abbas AK, Murphy KM, Sher A: Functional diversity of helper $T$ lymphocytes. Nature 1996, 383:787-793

63. Engwerda CR, Kaye PM: Organ-specific immune responses associated with infectious disease. Immunol Today 2000, 21:73-78

64. Squires KE, Schreiber RD, McElrath MJ, Rubin BY, Anderson SL, Murray HW: Experimental visceral leishmaniasis: role of endogenous IFN-gamma in host defense and tissue granulomatous response. J Immunol 1989, 143:4244-4249

65. Murray HW, Squires KE, Miralles CD, Stoeckle MY, Granger AM, Granelli-Piperno A, Bogdan C: Acquired resistance and granuloma formation in experimental visceral leishmaniasis. Differential T cell and lymphokine roles in initial versus established immunity. J Immunol 1992, 148:1858-1863

66. Tumang MC, Keogh C, Moldawer LL, Helfgott DC, Teitelbaum R, Hariprashad J, Murray HW: Role and effect of TNF-alpha in experimental visceral leishmaniasis. J Immunol 1994, 153:768-775

67. Bogdan C: Nitric oxide and the immune response. Nat Immunol 2001, 2:907-916

68. Weinstock JV, Boros DL: Organ-dependent differences in composition and function observed in hepatic and intestinal granulomas isolated from mice with Schistosomiasis mansoni. J Immunol 1983, 130:418-422

69. King CL, Xianli J, Stavitsky AB: Murine schistosomiasis mansoni: coordinate cytokine regulation and differences in cellular immune responses of granuloma cells and splenocytes to endogenous and exogenous schistosome egg antigens. Parasite Immunol 2001, 23:607-615

70. Hesse M, Piccirillo CA, Belkaid Y, Prufer J, Mentink-Kane M, Leusink M, Cheever AW, Shevach EM, Wynn TA: The pathogenesis of schistosomiasis is controlled by cooperating IL-10-producing innate effector and regulatory T cells. J Immunol 2004, 172:3157-3166

71. Stadecker MJ, Kamisato JK, Chikunguwo SM: Induction of T helper cell unresponsiveness to antigen by macrophages from schistosomal egg granulomas. A basis for immunomodulation in schistosomiasis? J Immunol 1990, 145:2697-2700

72. Flores Villanueva PO, Harris TS, Ricklan DE, Stadecker MJ: Macrophages from schistosomal egg granulomas induce unresponsiveness in specific cloned Th-1 lymphocytes in vitro and down-regulate schistosomal granulomatous disease in vivo. J Immunol 1994, 152:1847-1855

73. Hesse M, Modolell M, La Flamme AC, Schito M, Fuentes JM, Cheever AW, Pearce EJ, Wynn TA: Differential regulation of nitric oxide synthase-2 and arginase- 1 by type 1/type 2 cytokines in vivo: granulomatous pathology is shaped by the pattern of L-arginine metabolism. J Immunol 2001, 167:6533-6544

74. La Flamme AC, Patton EA, Bauman B, Pearce EJ: IL-4 plays a crucial role in regulating oxidative damage in the liver during schistosomiasis. J Immunol 2001, 166:1903-1911

75. Iniesta V, Gomez-Nieto LC, Corraliza I: The inhibition of arginase by $\mathrm{N}$ (omega)-hydroxy-l-arginine controls the growth of Leishmania inside macrophages. J Exp Med 2001, 193:777-784

76. Iniesta V, Gomez-Nieto LC, Molano I, Mohedano A, Carcelen J, Miron C, Alonso C, Corraliza I: Arginase I induction in macrophages, triggered by Th2-type cytokines, supports the growth of intracellular Leishmania parasites. Parasite Immunol 2002, 24:113-118

77. Mukhopadhyay R, Madhubala R: Leishmania donovani: cellular control of ornithine decarboxylase in promastigotes. Int $\mathrm{J}$ Biochem Cell Biol 1995, 27:947-952 